\title{
Rebirth and regeneration
}

\section{Japan's Center for Developmental Biology aims to become a world leader in regenerative medicine. It also wants to break with a system blamed for stifling the creativity of young researchers. David Cyranoski reports.}

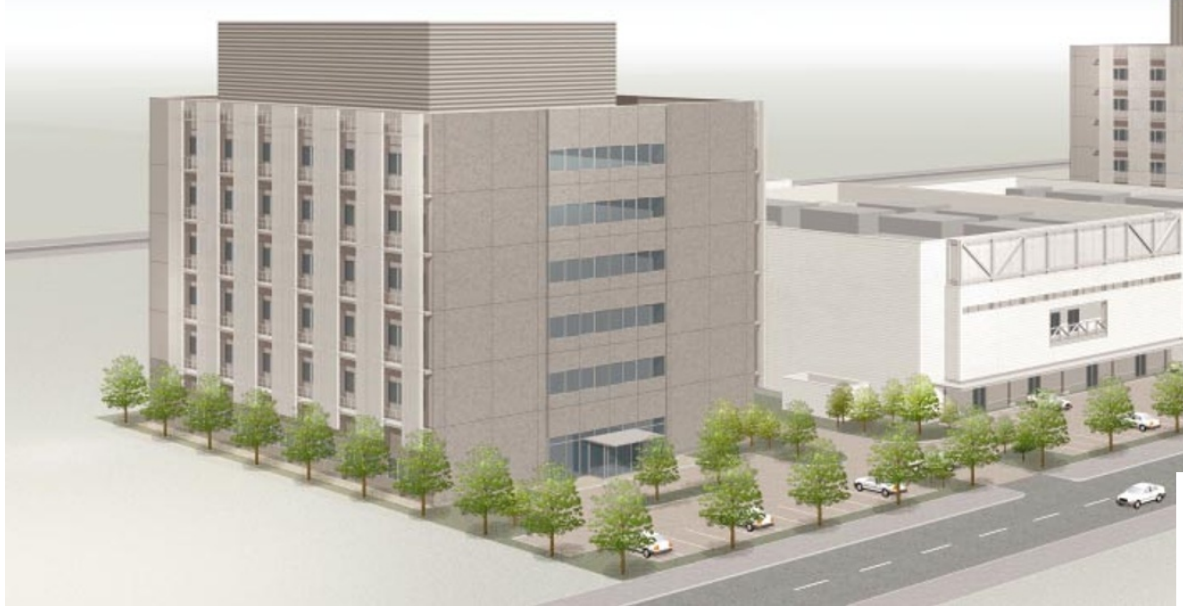

$\mathrm{R}$ emember Cumulina, the world's first cloned mouse? Even if you do, you might not remember the name of Teruhiko Wakayama, whose painstaking work made her birth possible.

In 1997, while a postdoc in Ryuzo Yanagimachi's lab at the University of Hawaii in Honoulu, Wakayama pioneered the technique for extracting nuclei from adult mouse cells and injecting them into eggs that underpinned the team's cloning success. His magic hands have since found employment at Rockefeller University in New York and Advanced Cell Technology of Worcester, Massachusetts, a biotech company that is famous for its cloning research.

But now, the 33-year-old Wakayama is going home to Japan to establish his own lab. He plans to investigate why cloning has such a low success rate, why many cloned animals die in the womb or shortly after birth, and how adult patterns of gene expression are reset by the cloning process. "I want to understand the

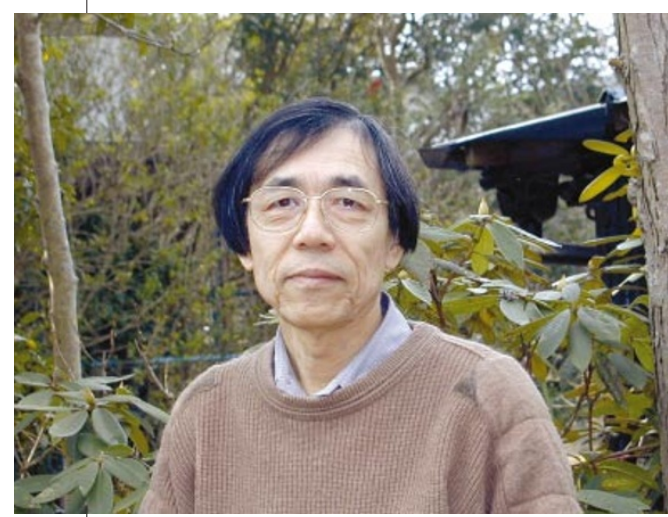

Free spirits: centre director Masatoshi Takeichi wants group leaders to pursue their own interests. mechanisms of reprogramming," he says.

Wakayama's career history makes him an emblem of the institute he is joining, the Center for Developmental Biology (CDB) in Kobe. The CDB has been created to propel Japan to the forefront of the emerging field of regenerative medicine - the cocktail of stem-cell research, cloning and traditional developmental biology that aims to find ways of growing replacement tissues for those lost to age or disease.

\section{Creative drive}

Significantly, the CDB has also placed a strong emphasis on youth and creativity, giving its group leaders autonomy to develop their own projects. In Japan, where established institute directors and professors typically hold sway, this is unusual. Indeed, many researchers blame the hierarchical culture of Japanese science for its failure to shine quite as brightly as the government's investment should allow and for driving frustrated talent abroad.

In luring back a rising star such as Wakayama, then, the CDB has already made a point. "This is an exciting experiment to establish a new institute merging basic and medical developmental biology, as well as creating an environment that has been generally difficult to find in our universities," enthuses its director, Masatoshi Takeichi.

As well as having been established to develop regenerative therapies for Japan's ageing population, the $\mathrm{CDB}$ is part of an effort to regenerate the city of Kobe, which was devastated by an earthquake in 1995. Located on an island of reclaimed land in the city's harbour, the centre’s four buildings cost some $¥ 7.1$ billion (US\$53 million) to construct. They are

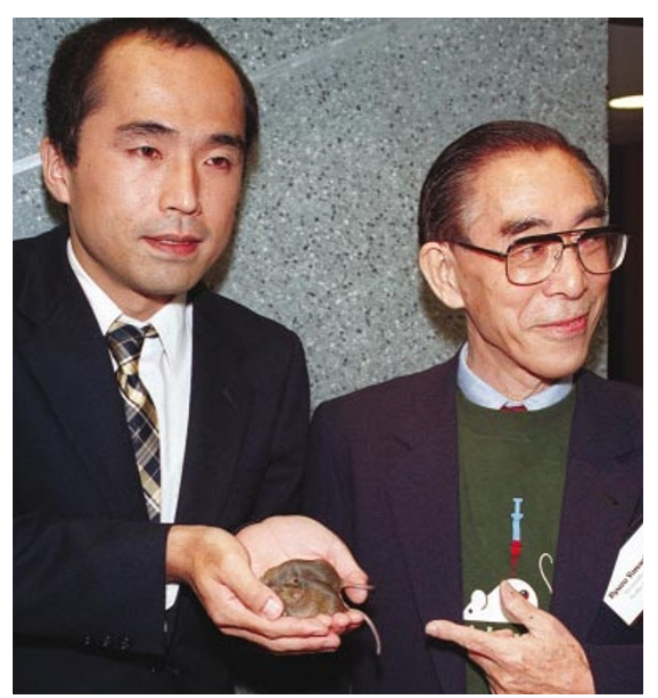

Mouse proud: Teruhiko Wakayama (left) and Ryuzo Yanagimachi show off their cloned animals.

packed with state-of-the-art equipment for cultivating and manipulating cells and tissues. The CDB's transgenic-mouse facility will house up to 150,000 experimental animals, and within 18 months the institute will gain a new bioinformatics centre. "It should be quite spectacular," says developmental geneticist Matthew Scott, who heads the multidisciplinary Bio-X facility that is being launched at Stanford University in California.

But the CDB's ability to shed the stiff suit of the Japanese academic system will be crucial. "Japan has excellent scientists, but the current structure of the system does not always encourage independence in young investigators," says Cliff Tabin, a developmental biologist at Harvard University. "Consequently, their contributions have been less than what one might have expected."

The CDB will have a core research programme run by Takeichi and six other senior group directors. But it is to the 20-plus 
independent team leaders - of whom Wakayama is one - that the institute's senior managers are entrusting the centre's future. "We will give young researchers a degree of independence and use of facilities that is unknown in Japan," claims Yoshiki Sasai, one of the CDB's group directors. Averaging in their late thirties, team leaders will be given enough funding to hire three postdocs and two technicians. Collectively, their efforts have been dubbed the CDB's "creativeresearch-promoting programme".

The CDB has provided a unique opportunity for Wakayama, who says that his youth and the fact that he graduated from an unfashionable provincial university would normally rule out gaining an independent position in Japan. "The CDB evaluates you based on your work, rather than your university's name or your age," he says.

In establishing its modus operandi, the $\mathrm{CDB}$ has drawn on the experience of a previous effort to break the Japanese research mould: the Brain Science Institute (BSI) in Saitama, north of Tokyo, which was launched in 1997. Both are initiatives of RIKEN, Japan's Institute of Physical and Chemical Research - and, like the CDB, the BSI was established to give Japan a worldclass centre in a hot scientific field. The BSI arranges its 36 teams into 11 groups, each with a director. But the team leaders all have great independence and interact without the rigid hierarchy that is typical of Japanese research centres.

This spring will be a decisive time for both institutes - the CDB will mark its official opening by holding a symposium in April, just as most of the BSI's research teams are up for their critical five-year review.

In putting its researchers on five-year contracts, and making the continuation of research teams dependent on evaluation, the BSI broke with Japanese tradition. One group has already been sent packing. "The review committee said it didn't need to exist," says

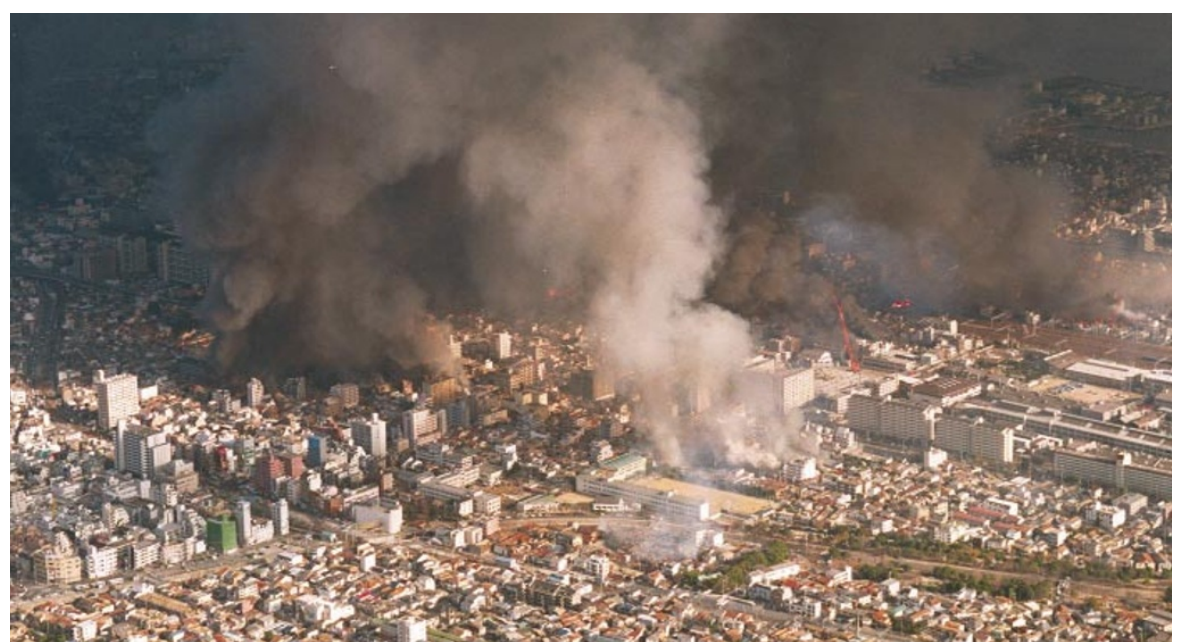

Phoenix from the flames: the construction of the Center for Developmental Biology (top) is part of the wider regeneration of Kobe in the wake of the city's devastation by an earthquake in 1995 (above).

one BSI researcher. This is revolutionary in Japan, where harsh criticism is rare and most researchers stay in one place for life. "Reviewing must be like this, however heartless it may look, in order to maintain a high standard," says BSI director Masao Ito.

But unsurprisingly, many BSI lab heads are concerned about the imminent reviews, and worry that discarded researchers will struggle to find work. "I'm not sure Japan is ready for this. It's just not that fluid," says one.

\section{Testing times}

The CDB faces an even more daunting review three years from now. As one of Japan’s Millennium Projects — a ¥120.6billion package set aside for science and technology initiatives - continuation after 2005 depends on a successful evaluation in that year.

Japan's current economic woes have also added to the pressure. The commercial application of research results is now a top priority for the Japanese government. Whereas the BSI merely had to establish itself as a major player in basic neuroscience - a task in which it has had reasonable success the CDB is supposed to feed a 'biomedical cluster' that will commercialize its results and bring them to clinical fruition.

The CDB is connected by a 10 -metre bridge to Kobe city's Institute of Biomedical Research and Innovation (IBRI), which opened last April and houses a hospital with 60 beds for clinical trials. The IBRI will share its reclaimed island with the Kobe International Business Center, which was launched

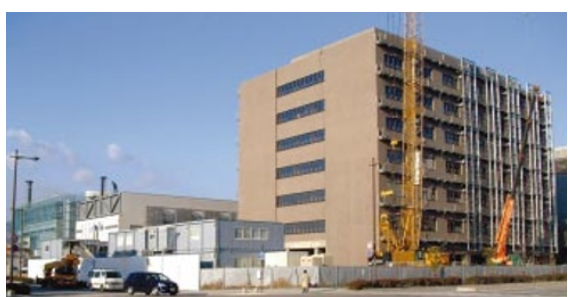

last July to lure companies to the area. A medical business centre will also be opened within 18 months.

Nevertheless, Takeichi and his colleagues stress that basic research will remain at the core of the CDB's activities. "Our major goal is to understand how individual cells are organized to form a higher-order complexity," says stem-cell biologist Shinichi Nishikawa, another of the centre's group directors.

The CDB's research will range broadly across the fields of development and regeneration. Nishikawa, for instance, will study the processes by which stem cells renew themselves, differentiate to form more specific cell types, and die. Sasai's group will study frogs, chicks and mice to examine mechanisms of brain development. Other researchers will examine fundamental developmental processes such as segmentation in the vertebrate body plan. Takeichi completes the picture, being a world leader in studying how cells within tissues stick together using molecules called cadherins.

But perhaps the CDB's biggest challenge will be to generate an image of a truly international institute that is attractive to foreigners. In this, the BSI has been a pioneer, conducting meetings in English and boasting a research staff of whom a quarter are foreign.

The CDB has some way to go. Despite heavy recruitment advertising at last July's International Congress of Developmental Biology in Kyoto, chaired by Takeichi, the CDB has only been able to fill two slots, while negotiating a possible third, with foreigners.

Some also say that the CDB still has a way to go in reaching out to researchers elsewhere in Japan, noting the dominance of biologists from Kyoto University - from which Takeichi, Nishikawa and Sasai all hail. "They are far too Kyoto-based and cliquish," says one biologist from the Tokyo area, claiming that applicants from outside the region of Kyoto, Osaka and Kobe have not been dealt a fair hand. Takeichi rejects these charges, attributing the dominance of Kyoto to the university's strength in developmental biology.

Given the challenges faced by the CDB, Takeichi urges critics not to rush to judgement. Although RIKEN president Shunichi Kobayashi says it is ridiculous to suppose that the CDB will be shut down in 2005, the short time that the centre will have to justify its existence clearly weighs on Takeichi's mind.

"I'm worried that people will do shortterm research and have many projects in parallel instead of concentrating on one in particular," he admits. "Our goal of creating regenerative medicine should be considered as a long-term project -10 to 20 years. Evaluations should be made on this basis." David Cyranoski is Nature's Asian Pacific correspondent. Center for Developmental Biology 